\title{
Cell fusing agent virus (Flavivirus) infection in Aedes aegypti in Texas: seasonality, comparison by trap type, and individual viral loads
}

\author{
Estelle Martin ${ }^{1,2}$ - Wendy Tang ${ }^{1} \cdot$ Cierra Briggs ${ }^{1} \cdot$ Helena Hopson $^{1} \cdot$ Jose G. Juarez $^{1} \cdot$ Selene M. Garcia-Luna ${ }^{1}$. \\ Megan Wise de Valdez ${ }^{3} \cdot$ Ismael E. Badillo-Vargas $^{4} \cdot$ Monica K. Borucki $^{5} \cdot$ Matthias Frank $^{5}$. Gabriel L. Hamer ${ }^{1}$
}

Received: 23 September 2019 / Accepted: 10 April 2020 / Published online: 21 May 2020

(c) The Author(s) 2020

\begin{abstract}
South Texas has experienced local transmission of Zika virus and of other mosquito-borne viruses such as chikungunya virus and dengue virus in the last decades. Using a mosquito surveillance program in the Lower Rio Grande Valley (LRGV) and San Antonio, TX, from 2016 to 2018, we detected the presence of an insect-specific virus, cell fusing agent virus (CFAV), in the Aedes aegypti mosquito population. We tested 6,326 females and 1,249 males from the LRGV and 659 females from San Antonio for CFAV by RT-PCR using specific primers. Infection rates varied from 0 to 261 per 1,000 mosquitoes in the LRGV and 115 to 208 per 1,000 in San Antonio depending on the month of collection. Infection rates per 1,000 individuals appeared higher in females collected from BG Sentinel 2 traps compared to Autocidal Gravid Ovitraps, but the ratio of the percentage of infected pools did not differ by trap type. The natural viral load in individual males ranged from $1.25 \times 10^{2}$ to $5.50 \times 10^{6}$ RNA copies and in unfed females from $5.42 \times 10^{3}$ to $8.70 \times 10^{6}$ RNA copies. Gravid females were found to harbor fewer viral particles than males and unfed females.
\end{abstract}

\section{Introduction}

In the continental United States, the states of Florida and Texas are emerging hotspots for Aedes aegypti-driven virus transmission. The Texas-Mexico border region has experienced local epidemics of dengue virus (DENV) in multiple communities [1-4]. In 2015, local transmission of chikungunya virus (CHIKV) occurred in Brownsville, TX, and 10

Handling Editor: Tim Skern.

Estelle Martin

estellemartin@ufl.edu

$\triangle$ Gabriel L. Hamer

ghamer@tamu.edu

1 Department of Entomology, Texas A\&M University, College Station, TX, USA

2 Department of Entomology and Nematology, University of Florida, Gainesville, FL, USA

3 Department of Science and Mathematics, Texas A\&M University-San Antonio, San Antonio, TX, USA

4 Department of Entomology, Texas A\&M AgriLife Research, Weslaco, TX, USA

5 Lawrence Livermore National Laboratory, Livermore, CA, USA cases of Zika virus (ZIKV) were documented in South Texas by the Texas Department of State Health Services between 2016 and $2017[5,6]$.

Arbovirus disease transmission has been observed to vary from region to region [7, 8]. For example, DENV transmission in Tamaulipas, Mexico, during an epidemic period can amount to thousands of cases, while on the other side of the border in the Rio Grande Valley of Texas, United States, very few cases are recorded [4]. Disease dynamics are influenced by intrinsic and extrinsic factors among which the presence of microbes in the mosquito vector could enhance or reduce viral transmission $[9,10]$. In the last decade, insect-specific viruses (ISVs) in mosquitoes have been shown to modulate the transmission of human pathogens (reviewed in reference [11]). However, ISVs can only infect and replicate in insect cells, causing no disease in humans [12]. The first ISV discovered was cell fusing agent virus (CFAV) (1974), which belongs to the classical ISVs [12]. Since its isolation from a natural mosquito population in Puerto Rico, United States [13], CFAV has been reported in multiple other countries, including Thailand [14], Indonesia [15], and Mexico [16]. While CFAV has been detected in field-collected mosquitoes, we are still lacking information regarding the prevalence and seasonality of infection in natural mosquito populations. In this study, we describe 
the infection rate of CFAV in Ae. aegypti populations from the Lower Rio Grande Valley (LRGV) and San Antonio, TX. Additionally, we evaluate the correlation of trap type, sex, and physiological status with the infection rate (IR) and the viral load in individual male and female Ae. aegypti mosquitoes.

\section{Materials and methods}

\section{Mosquito sampling}

Mosquito sampling using Autocidal Gravid Ovitraps (AGO) in the LRGV of South Texas was performed in seven communities (Balli, Cameron, Mesquite, Chapa, Christian Ct., La Vista and Rio Rico) located in Hidalgo County and one community (La Bonita) in Cameron County (Fig. 1) as described previously [6]. Briefly, AGOs baited with hay infusion were deployed inside and outside homes and sampled weekly. For mosquito sampling, BG Sentinel 2 traps (BGS2) with BG Lure (Biogents AG, Regensburg, Germany) were deployed in the community of La Piñata, Donna, TX, at 50 and 15 private residences in 2017 and 2018, respectively. In San Antonio, TX, BGS2 traps were deployed at 10 (2017) and 27 (2018) private residences across different ecological and socio-economical regions (Fig. 1). In both La Piñata and San Antonio, mosquitoes were sampled weekly (set in the morning and retrieved about 24 hours later). The species and sex of the mosquitoes from the AGO and BGS2 traps were determined and the mosquitoes from the BGS2 traps were additionally sorted by physiological status, and pools were stored at $-80^{\circ} \mathrm{C}$ until virus testing. To test for CFAV, we used a subset of Ae. aegypti that had been tested previously for ZIKV/CHIKV using a multiplex qRT-PCR assay [6]. Mosquito pools were homogenized in Hank's buffer salt solution (HBSS) (Thermo Fisher Scientific, Waltham, MS) using a Tissuelyser II (QIAGEN, Hilden, Germany) and a stainless steel bead and then centrifuged for $1 \mathrm{~min}$ at 12,000 rpm. Subsequently, RNA was extracted from $250 \mu \mathrm{L}$ of supernatant using a MagMAX ${ }^{\mathrm{TM}}$ CORE Nucleic Acid Purification Kit (Applied Biosystems, Foster City, California) following the manufacturer's instructions. Individual mosquitoes used for the quantification of CFAV in the natural population were processed using the same protocol.

\section{Virus detection}

In this study, we tested new samples from the LRGV and San Antonio (see above) using a conventional PCR assay with specific primers targeting a portion of the envelope gene of CFAV and a SuperScript ${ }^{\mathrm{TM}}$ IV VILO ${ }^{\mathrm{TM}}$ Master Mix with ezDNase $^{\mathrm{TM}}$ Enzyme Kit (Thermo Fisher, Waltham, MA) to
Fig. 1 Study area and study sites for the collection of $A e$. aegypti mosquitoes in the Lower Rio Grande Valley and San Antonio using AGO and BGS2 traps in 2017 to 2018. The map was made using QGIS 3.4.4 (https://qgis.org/en/site/). Map data: Google Maps, and with publicly available administrative boundaries (https://gadm. org/license.html)

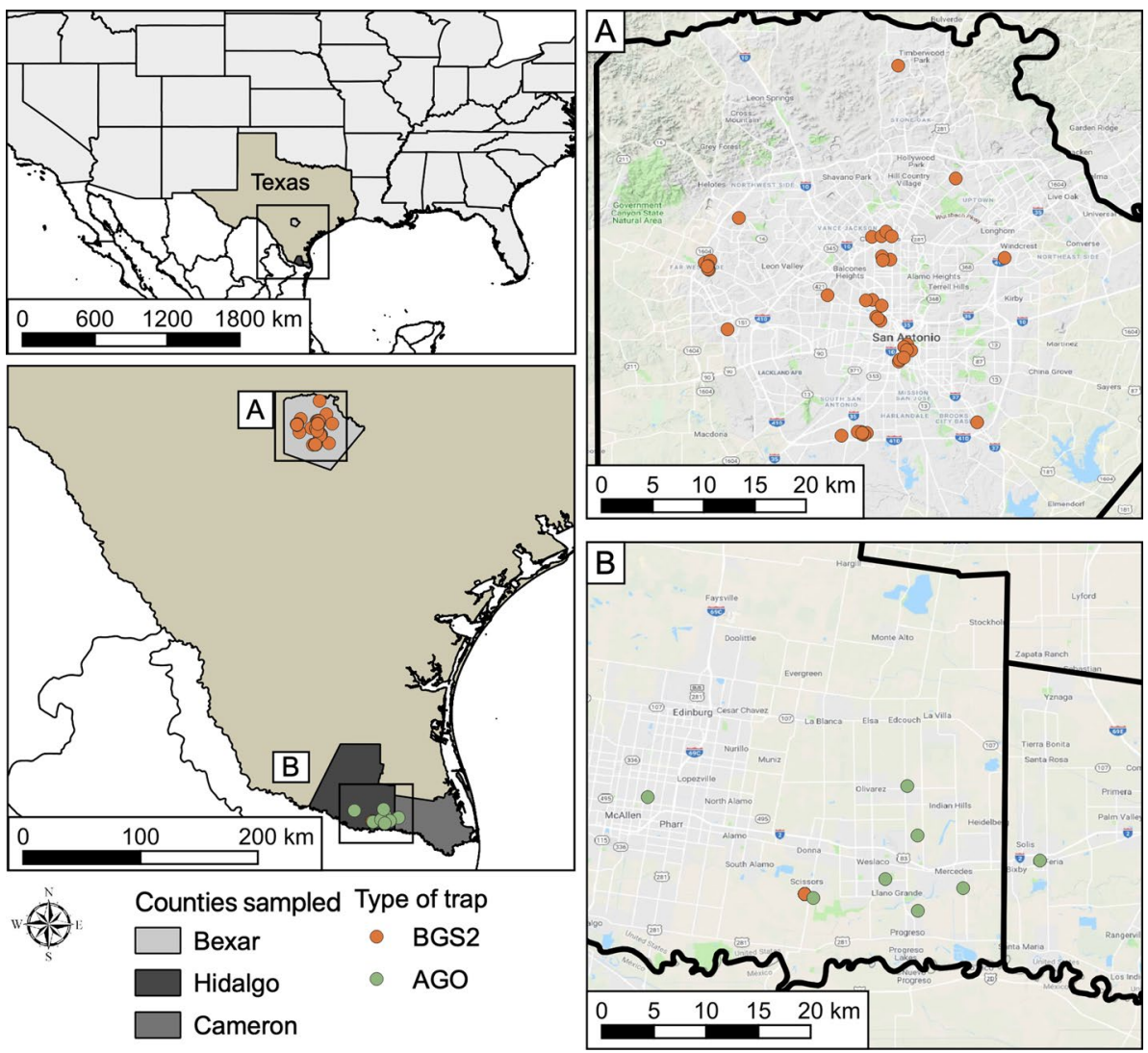


screen Ae. aegypti mosquito pools and individuals for CFAV [17]. Briefly, $0.5 \mu \mathrm{l}$ of ezDNase and $0.5 \mu \mathrm{l}$ of $10 \mathrm{X}$ ezDNAse Buffer were added to $4 \mu \mathrm{L}$ of RNA to remove genomic DNA from the RNA preparation $\left(2 \mathrm{~min}\right.$ at $\left.37{ }^{\circ} \mathrm{C}\right)$. Five microliters of the cleaned RNA was used for cDNA synthesis using SuperScript ${ }^{\mathrm{TM}}$ IV VILO ${ }^{\mathrm{TM}}$ Master Mix. Two microliters of a 1:10 dilution of the cDNA was then amplified by PCR using the following cycling parameters: $94^{\circ} \mathrm{C}$ for $3 \mathrm{~min}, 38$ cycles of $94{ }^{\circ} \mathrm{C}$ for $30 \mathrm{~s}, 55^{\circ} \mathrm{C}$ for $30 \mathrm{~s}, 72^{\circ} \mathrm{C}$ for $1 \mathrm{~min}$, and a final extension step at $72{ }^{\circ} \mathrm{C}$ for $8 \mathrm{~min}$.

PCR products were run on $2 \%$ agarose gel for $20 \mathrm{~min}$, and positive samples were purified using Exo SAP-IT PCR Product Cleanup (Affymetrix, Santa Clara, CA) and sequenced. The sequences that were obtained were aligned, cleaned, and subjected to a BLAST search against the NCBI database using Geneious version 9.1.8. Sequences showing more than 98\% identity were assigned to viral species. Additionally, positive samples were confirmed using a second PCR assay targeting the NS5 gene of CFAV [13]. The cycling protocol consisted of $95{ }^{\circ} \mathrm{C}$ for 2 min followed by 35 cycles of $94{ }^{\circ} \mathrm{C}$ for $30 \mathrm{~s}, 50{ }^{\circ} \mathrm{C}$ for $30 \mathrm{~s}$, and final elongation at $72{ }^{\circ} \mathrm{C}$ for $1 \mathrm{~min}$ and $72{ }^{\circ} \mathrm{C}$ for $8 \mathrm{~min}$. A subset of the amplicons were then sequenced by Eton Bioscience Inc. (San Diego, CA) using forward and reverse primers. To quantify the CFAV load in individual mosquitoes, we designed a gBlock (available upon request) to use as a standard for the qPCR analysis based on the PCR procedure described above [17] and a complete genome sequence of CFAV (accession no. NC_001564) in Geneious. Briefly, we used a Power SYBR Green RNA-To-Ct 1 Step Kit (Applied Biosystems, Foster City, CA) with $5 \mu \mathrm{L}$ of RNA, $1 \mu \mathrm{L}$ of each forward and reverse primer at $10 \mu \mathrm{M}$ with the following cycling protocol: $48{ }^{\circ} \mathrm{C}$ for $30 \mathrm{~min} ; 95^{\circ} \mathrm{C}$ for $10 \mathrm{~min}$, and 40 cycles at $95^{\circ} \mathrm{C}$ for $15 \mathrm{~s}$ and $60{ }^{\circ} \mathrm{C}$ for $1 \mathrm{~min}$.

\section{CFAV infection rates (IRs)}

We estimated the CFAV IRs using the maximum-likelihood estimation (MLE) with 95\% confidence intervals (CI) [18]. IRs were calculated per month for the mosquitoes collected from the LRGV using AGO traps and per week for the mosquito collected from the LRGV and
San Antonio using BGS2 traps. To allow direct comparison, IRs for mosquitoes collected using AGO traps in the LRGV were also calculated per week of study.

\section{Statistical analysis}

Statistical analysis was performed in GraphPad Prism version 7.0 for Mac (Graphpad Software, San Diego, California, USA). Variation in the mean virus load was tested using an unpaired $t$-test resulting in an exact $P$-value and 95\% confidence interval. Comparison of the proportion of CFAV-infected pools was done using a chi-square $\left(\mathrm{X}^{2}\right)$ test.

\section{Results}

\section{Cell fusing agent virus detection and infection rate in Ae. aegypti collected in 2017-2018}

In the LRGV, 580 pools representing 5,215 individual $A$ e. aegypti mosquitoes were collected from AGO traps. Specifically, 205 pools (2,161 Ae. aegypti females) were captured from March to December 2017, and 375 pools (3,054 Ae. aegypti females) were collected from January to December 2018 (Table 1). The IR (per 1,000 individuals) per month ranged from 7.3 in October to 95.7 in March for 2017 and from 0 in February to 158.1 in December for 2018 (Fig. 2). CFAV infection was consistent throughout the months of sampling with no clear evidence of seasonal structure. A non-significant difference was observed in monthly IR between 2017 and $2018(p>0.05)$.

In San Antonio, 659 mosquitoes were collected from BGS2 traps and tested for CFAV infection. In 2017, we detected CFAV in June (IR $=208.6[95 \%$ CI $=135.3$ 308]). Meanwhile, in 2018, CFAV was detected in May, June and July, with an IR of 151.1 (95\% CI $=95.4-$ 230.41), $182(95 \% \mathrm{CI}=120.3-273.3)$ and $115.3(95 \% \mathrm{CI}=$ 67.70-188.8), respectively. No statistical difference in the
Table 1 Detection of CFAV in Ae. aegypti mosquitoes from the LRGV and San Antonio collected using AGO and BGS2 traps in 2017 and 2018

\begin{tabular}{llllllc}
\hline Location & $\begin{array}{l}\text { Collection } \\
\text { method }\end{array}$ & Year of collection & Sex & $\begin{array}{l}\text { Number of } \\
\text { mosquitoes }\end{array}$ & $\begin{array}{l}\text { Number of } \\
\text { mosquito pools }\end{array}$ & $\begin{array}{l}\text { Number of } \\
\text { positive pools }\end{array}$ \\
\hline LRGV & AGO & 2017 (Mar.-Dec.) & Female & 2161 & 205 & 87 \\
& & 2018 (Jan.-Dec.) & Female & 3054 & 375 & 124 \\
& BGS2 & 2018 (Sep.-Nov.) & Female & 1111 & 399 & 119 \\
& BGS2 & 2018 (Sep.-Nov.) & Male & 1249 & 330 & 77 \\
San Antonio & BGS2 & 2017 (Jun.) & Female & 106 & 33 & 17 \\
& & 2018 (May-Jul.) & Female & 553 & 105 & 54 \\
\hline
\end{tabular}




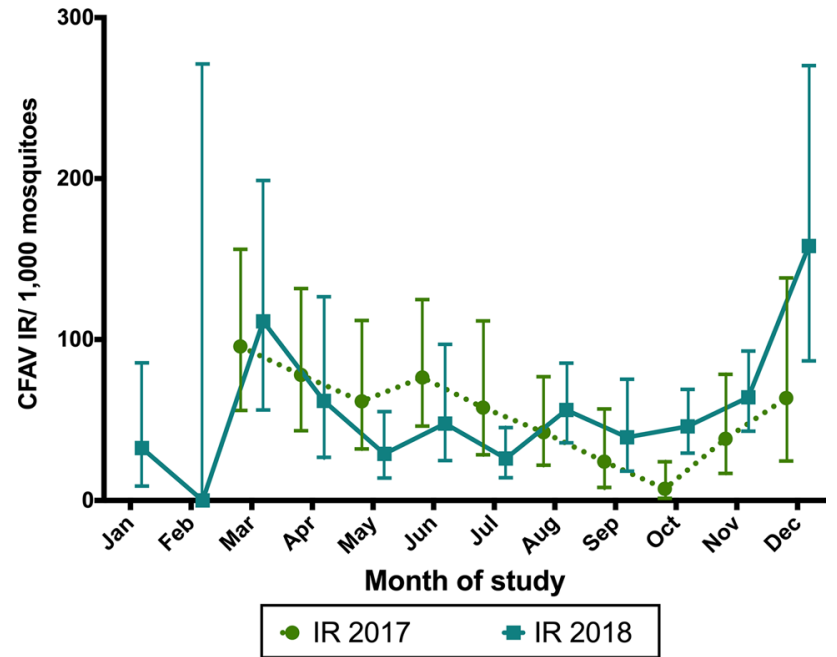

Fig. 2 CFAV infection rates (IRs) per month of study in Ae. aegypti females from the LRGV collected using AGO traps in 2017 to 2018. The data points indicate the average CFAV IR per 1000 values observed, and the bars indicate the full range of CFAV IR per 1000 values observed

proportion of CFAV-infected pools was observed between 2017 and 2018 for the month of June $(p=0.63)$.

\section{Influence of the trap type on the detection of CFAV in the LRGV}

In order to compare the CFAV IR according to trap type, 138 Ae. aegypti female pools representing 1,013 mosquitoes captured in AGO traps and 379 pools representing 1,076 females captured in BGS2 traps were tested. Both trap types were set up from epidemiological week (EW) 37-46 of 2018 in several communities of Hidalgo and Cameron counties, allowing a direct comparison. Forty of the pools collected using AGO traps and 113 pools collected using BGS2 traps were positive for CFAV. The AGO IR averaged 48.4 (95\% $\mathrm{CI}=16.4-112.3)$ and the BGS2 IR averaged 122.6 (95\% CI $=85.8$-148.6) (Fig. 3). Overall, the average IR was higher for the mosquitoes collected in BGS2 traps than for those collected in AGO traps $(p<0.0001)$. A week-to-week comparison showed a higher CFAV IR when mosquito pools were collected from BGS2 traps as compared to AGO traps, except for EW 40; however, the ratio of the number of CFAV-positive pools did not differ by trap type $(p>0.05)$.

\section{CFAV infection rate by sex and physiological status}

Ae. aegypti mosquitoes collected during the EW 37 to 46 of 2018 with BGS2 traps in the LRGV were further analyzed by sex and physiological status. The CFAV IR ranged from 32 to 206 (in male mosquitoes average $=85.8 \pm 17.7$ ), from 58 to 261 in unfed females (average $=128 \pm 16$ ), and from 0

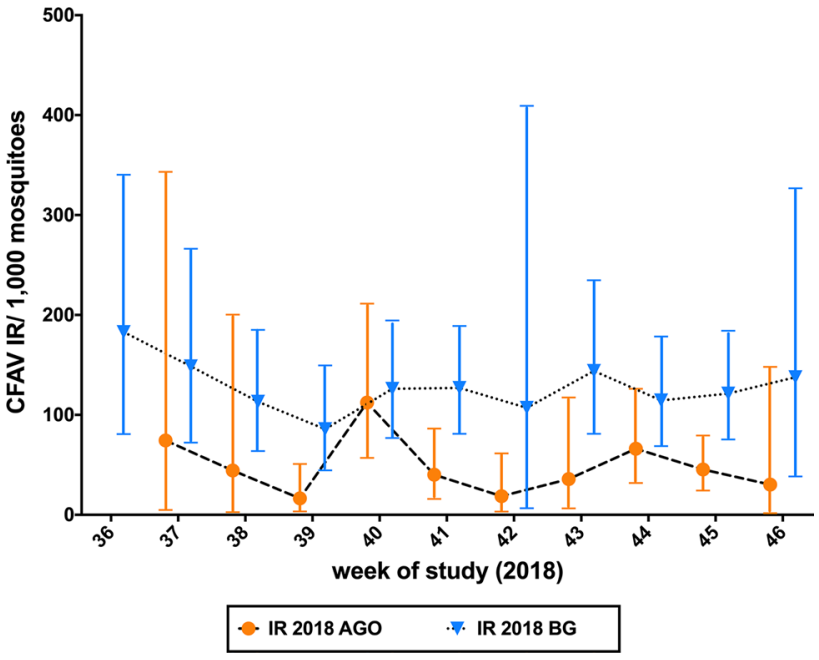

Fig. 3 Comparison of infection rates (IRs) in Ae. aegypti from the LRGV collected in BGS2 and AGO traps in 2018. The data points indicate the average CFAV IR per 1000 values observed, and the bars indicate the full range of CFAV IR per 1000 values observed

to 215 in gravid females (mean $=129 \pm 19$ ) (Fig. 4). While overall, the average IR in males was lower than in females, the difference was not significant ( $p=0.08$ compared to unfed females and $p=0.09$ compared to fed females). Additionally, the proportion of infected pools was not statistically different between the different groups ( $p>0.05$ ).

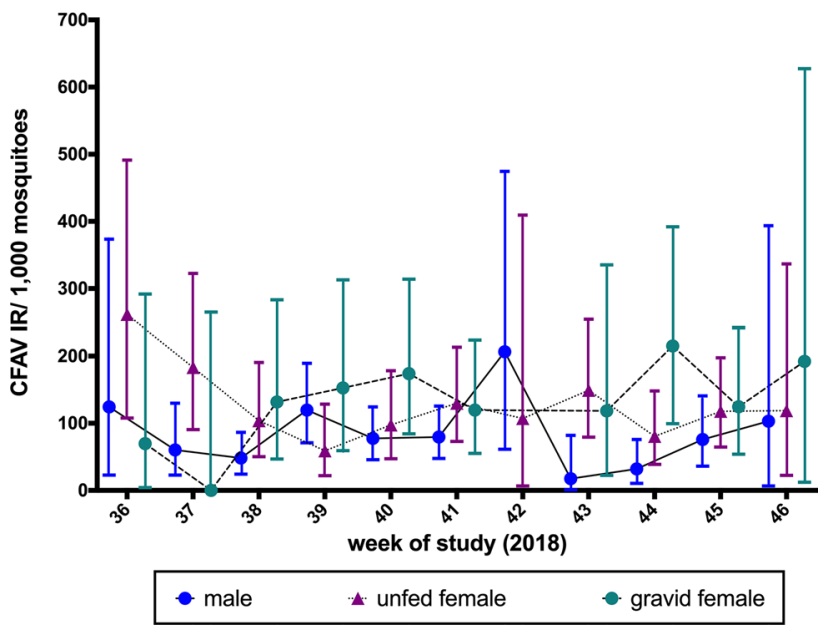

Fig. 4 Comparison of infection rates (IRs) in male and female Ae. aegypti of different physiological stages captured in BGS2 traps in 2018. The data points indicate the average CFAV IR per 1000 values observed, and the bars indicate the full range of CFAV IR per 1000 values observed 


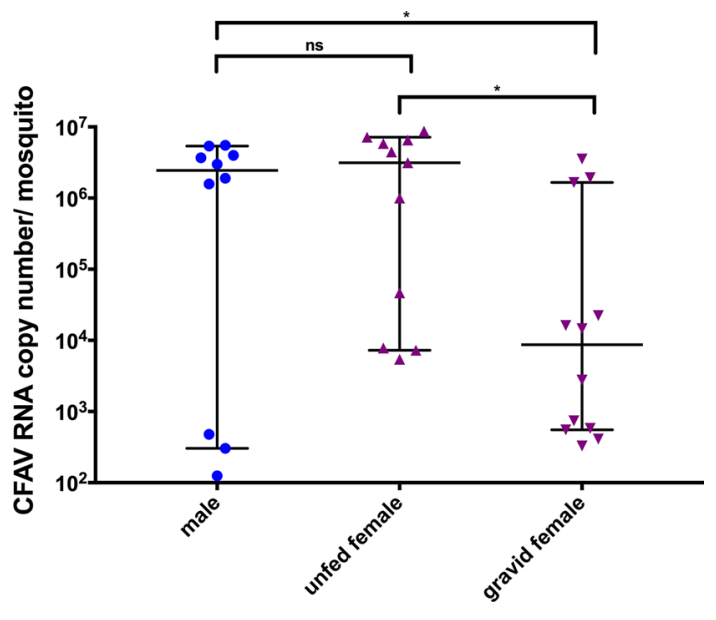

Fig. 5 Median with 95\% CI of the CFAV load in individual male and female Ae. aegypti of different physiological stages captured in BGS2 traps in 2018

\section{CFAV load in naturally infected individual mosquitoes}

The viral load in individual mosquitoes of different sex and physiological status collected from BGS2 traps in the LRGV was determined (Fig. 5). The viral titer is expressed as CFAV RNA genome equivalents. Overall, no statistical difference was observed between males $(\mathrm{n}=10)$ and unfed females $(\mathrm{n}=11 ; p=0.49)$. The CFAV load for males ranged from $1.25 \times 10^{2}$ to $5.50 \times 10^{6}$ RNA copies per mosquito, and for females from $5.42 \times 10^{3}$ to $8.70 \times 10^{6}$ RNA copies per mosquito. A statistical difference was observed between gravid females ( $3.29 \times 10^{2}$ to $3.53 \times 10^{6}$ RNA copies per mosquito) and unfed females $(p=0.0134)$ as well as between gravid females and males $(p=0.015)$.

\section{Discussion}

Although CFAV was discovered more than 40 years ago in an infected Ae. aegypti cell culture, its first detection in mosquito pools was in Puerto Rico in 2006 [13]. The virus was then detected in Thailand in 2007 and 2013 [14,1 9], Indonesia in 2009 [15], Mexico in 2011 [16], in Brazil and Australia in 2018 [20, 21] and in Africa in 2003 [22, 23]. In a previous study, we detected the presence of CFAV in two Ae. aegypti populations from Texas using a microarray developed at the Lawrence Livermore National Laboratory [24]. Although CFAV has been detected in the field on multiple occasions, few studies have provided an estimate of the infection rate in field populations of mosquitoes. Our study reveals the presence of CFAV throughout the year in Ae. aegypti collected using AGO traps in the LRGV (mean IR for $2017=54.5$, mean IR for $2018=56.0$ ) and at least from May to July for the San Antonio population collected using BGS2 traps (mean IR for $2017=208.6$, mean IR for $2018=166.8$ ). This study provides evidence that CFAV is widely distributed in Texas, although a direct comparison of IRs was not possible among the LRGV and San Antonio sites given that BGS2 trapping was performed at different time points. A previous study also documented CFAV in Aedes mosquitoes collected in Galveston, TX, in 2012 [25], adding to the overall picture of the geographic distribution of CFAV in Texas. Infection rates of CFAV were previously reported in an Ae. aegypti mosquito population from Thailand at a much lower rate, with an IR of $6.2(\mathrm{n}=2110)$ in 2008 and $8.2(n=1944)$ in 2012 [14]. Differences in IRs could be due to the methodology used. In our study, mosquito homogenates were tested by PCR using gene-specific primers, whereas in the other study, mosquito homogenates were first screened for cytopathic effect in C6/36 cells, and only positive samples were tested by PCR using a pan-flavivirus assay followed by sequencing. Another insect-specific virus that infects Culex spp. mosquitoes, Culex flavivirus ( $\mathrm{CxFV}$ ), has received more research attention, and studies of infection rates and seasonality have been reported [26, 27]. In a study done in Iowa (USA), CxFV was not detected from May to June but occurred from July to October, while in Texas, the virus was detected from November to March with no detection during the months of April to August. A possible explanation for this seasonality relates to the overall number of mosquitoes collected and tested, which was reported for CxFV [28] and Aedes flavivirus (AeFV) [29] . In our study, an absence of CFAV was observed in the month of February 2018, when only nine pools (10 individual mosquitoes) were available for testing.

The infection rate of CFAV in the LRGV was compared using two trap types, AGO and BGS2. CFAV IRs from BGS2 traps were higher than those from AGO traps. IRs from BGS2 traps were $1.1-5.7$ times higher than those from AGO traps. BGS2 traps were originally developed to target host-seeking females and contents of the trap must be inspected after $24 \mathrm{~h}$ of trapping [30, 31], while AGO traps mainly target gravid females for which the contents of the trap can be checked weekly [32-34]. While the lower rates of infection in the AGO-collected mosquito pools could have been due to degradation of the viral RNA after a week of trapping, it is also possible that the physiological status of the females collected in the different traps influences the IR. In our study, gravid females did indeed harbor fewer viral particles than unfed females. This represents an unique observation, because very few studies have documented arboviral loads in naturally infected females from the field, in part because infected individuals are rarely detected and as a result are typically tested in pools to reduce costs [35]. However, there has been one report of the CxFV infection loads 
in a Culex pipiens colony naturally infected in Colorado [36]. It has been hypothesized that traps targeting gravid females should have a higher viral IR than traps targeting host-seeking females, given that gravid females are more likely to be on average older than unfed females and more likely to have had at least one bloodmeal [37]. While some studies comparing the West Nile virus IRs between gravid and unfed female Culex spp. mosquitoes did confirm this hypothesis [38, 39], other studies found no statistical differences or opposite results [40]. One possible explanation for the reduced viral loads in gravid females could be that the immune response in gravid females is different from that in unfed females. Variation in the mosquito immune response has been demonstrated following the ingestion of the bloodmeal or the production of eggs [41-43]. Also, we found variation in the individual virus load, with some mosquitoes harboring a low number of genome equivalent while others had higher copy numbers. This reflects the natural variation in the involvement of mosquitoes when mounting an immune response to CFAV infection. While AGO traps have been developed as mosquito population surveillance and control tools, we demonstrated that samples from this trap can also be used for viral surveillance. Due to its cost efficiency and reduced equipment and labor requirements, this study suggests that the AGO trap is a viable option for monitoring vector populations for viral infection, especially in remote locations or developing countries.

CFAV was detected in both male and female field-collected mosquitoes, confirming the vertical transmission of this virus $[13,14,17]$, a common mechanism for maintenance of ISVs such as CxFV [44, 45], AeFV [46] and Kamiti River virus [47].

To date, only one report has shown coinfection with CFAV and DENV (DENV-4) in field-collected mosquitoes [19]. In that study, mosquitoes $(n=93)$ were collected in the homes of DENV-infected patients, which might have increased the probability of detecting coinfection. No evidence of coinfection between CFAV and ZIKV or CHIKV has been observed. Our samples were tested previously for ZIKV and CHIKV during an arbovirus surveillance study from 2016 to 2018 and none were positive [6]. Several ISVs have demonstrated their importance in the modulation of the transmission of certain pathogens. For example, $\mathrm{CxFV}$ and Nhumirim virus both have the capacity to modulate WNV transmission by Culex mosquitoes [36, 48-50]. The ability of CFAV to influence DENV replication has been demonstrated in vitro [51,52], and its ability to influence arboviral disease transmission has been demonstrated in vivo for ZIKV and DENV by intrathoracic injection. In those studies, a reduction in arbovirus transmission was observed. Hence, if these observations are confirmed in the context of a natural infection (as opposed to intrathoracic injection), the low number of cases observed in the LRGV during the 20162017 ZIKV outbreak could be at least partially explained by the presence of CFAV in the Ae. aegypti population in that area. Therefore, additional studies on the geographic prevalence of CFAV in Ae. aegypti populations in Texas could help with the prediction of emergence of arboviral disease in the region.

Acknowledgements We are grateful to the residents of the Lower Rio Grande Valley and San Antonio, TX, who granted us permission to trap mosquitoes on their property. We also thank our field team of staff and students for the work in the LRGV and San Antonio: Ester Carbajal, Edwin Valdez, Courtney Avila, Joel Obregon, Oluwaseun Aloba, Michelle Ximenez, Estefany Villalobos, Janelle Garcia, Nacera Benslamine, Humberto Garcia, Alejandra Moya, Keren Hernandez, and Krista Lazo. We also thank the Texas Veterinary Medical Diagnostic Laboratory for the use of their equipment. This work was funded by Texas A\&M AgriLife Research Insect Vectored Diseases Seed Grant and Lawrence Livermore National Laboratory and was performed, in part, under the auspices of the U.S. Department of Energy by LLNL under Contract DE-AC52-07NA27344.

Open Access This article is licensed under a Creative Commons Attribution 4.0 International License, which permits use, sharing, adaptation, distribution and reproduction in any medium or format, as long as you give appropriate credit to the original author(s) and the source, provide a link to the Creative Commons licence, and indicate if changes were made. The images or other third party material in this article are included in the article's Creative Commons licence, unless indicated otherwise in a credit line to the material. If material is not included in the article's Creative Commons licence and your intended use is not permitted by statutory regulation or exceeds the permitted use, you will need to obtain permission directly from the copyright holder. To view a copy of this licence, visit http://creativecommons.org/licenses/by/4.0/.

\section{References}

1. Ramos MM, Mohammed H, Zielinski-Gutierrez E, Hayden MH, Lopez JL, Fournier M, Trujillo AR, Burton R, Brunkard JM, Anaya-Lopez L, Banicki AA, Morales PK, Smith B, Munoz JL (2005) Waterman SH (2008) Epidemic dengue and dengue hemorrhagic fever at the Texas-Mexico border: results of a household-based seroepidemiologic survey. Am J Trop Med Hyg 78(3):364-369

2. Clark GG (2008) Dengue and dengue hemorrhagic fever in northern Mexico and south Texas: do they really respect the border? Am J Trop Med Hyg 78(3):361-362

3. Brunkard JM, Robles Lopez JL, Ramirez J, Cifuentes E, Rothenberg SJ, Hunsperger EA, Moore CG, Brussolo RM, Villarreal NA, Haddad BM (2007) Dengue fever seroprevalence and risk factors, Texas-Mexico border, 2004. Emerg Infect Dis 13(10):1477-1483

4. Reiter P, Lathrop S, Bunning M, Biggerstaff B, Singer D, Tiwari T, Baber L, Amador M, Thirion J, Hayes J, Seca C, Mendez J, Ramirez B, Robinson J, Rawlings J, Vorndam V, Waterman S, Gubler D, Clark G, Hayes E (2003) Texas lifestyle limits transmission of dengue virus. Emerg Infect Dis 9(1):86-89

5. DSHS announces first Texas-acquired chikungunya case (2016). Texas Department of State Health Services

6. Martin E, Medeiros MCI, Carbajal E, Valdez E, Juarez JG, GarciaLuna S, Salazar A, Qualls WA, Hinojosa S, Borucki MK, Manley HA, Badillo-Vargas IE, Frank M, Hamer GL (2019) Surveillance 
of Aedes aegypti indoors and outdoors using autocidal gravid ovitraps in South Texas during local transmission of Zika virus, 2016 to 2018. Acta Trop 192:129-137

7. Tabachnick WJ (2016) Ecological effects on arbovirus-mosquito cycles of transmission. Curr Opin Virol 21:124-131

8. Perkins TA, Scott TW, Le Menach A, Smith DL (2013) Heterogeneity, mixing, and the spatial scales of mosquito-borne pathogen transmission. PLoS Comput Biol 9(12):e1003327

9. Valderrama A, Diaz Y, Lopez-Verges S (2017) Interaction of Flavivirus with their mosquito vectors and their impact on the human health in the Americas. Biochem Biophys Res Commun 492(4):541-547

10. Hegde S, Rasgon JL, Hughes GL (2015) The microbiome modulates arbovirus transmission in mosquitoes. Curr Opin Virol 15:97-102

11. Roundy CM, Azar SR, Rossi SL, Weaver SC, Vasilakis N (2017) Insect-specific viruses: a historical overview and recent developments. Adv Virus Res 98:119-146

12. Stollar V, Thomas VL (1975) An agent in the Aedes aegypti cell line (Peleg) which causes fusion of Aedes albopictus cells. Virology 64(2):367-377

13. Cook S, Bennett SN, Holmes EC, De Chesse R, Moureau G, de Lamballerie X (2006) Isolation of a new strain of the flavivirus cell fusing agent virus in a natural mosquito population from Puerto Rico. J Gen Virol 87(Pt 4):735-748

14. Yamanaka A, Thongrungkiat S, Ramasoota P, Konishi E (2013) Genetic and evolutionary analysis of cell-fusing agent virus based on Thai strains isolated in 2008 and 2012. Infect Genet Evol 19:188-194

15. Hoshino K, Isawa H, Tsuda Y, Sawabe K, Kobayashi M (2009) Isolation and characterization of a new insect flavivirus from Aedes albopictus and Aedes flavopictus mosquitoes in Japan. Virology 391(1):119-129

16. Espinoza-Gomez F, Lopez-Lemus AU, Rodriguez-Sanchez IP, Martinez-Fierro ML, Newton-Sanchez OA, Chavez-Flores E, Delgado-Enciso I (2011) Detection of sequences from a potentially novel strain of cell fusing agent virus in Mexican Stegomyia (Aedes) aegypti mosquitoes. Arch Virol 156(7):1263-1267

17. Contreras-Gutierrez MA, Guzman H, Thangamani S, Vasilakis N, Tesh RB (2017) Experimental infection with and maintenance of cell fusing agent virus (Flavivirus) in Aedes aegypti. Am J Trop Med Hyg 97(1):299-304

18. Biggerstaff B (2009) PooledInfRate, Version 4.0: a Microsoft Office Excel Add-In to compute prevalence estimates from pooled samples. Centers for Disease Control and Prevention, Fort Collins

19. Kihara Y, Satho T, Eshita Y, Sakai K, Kotaki A, Takasaki T, Rongsriyam Y, Komalamisra N, Srisawat R, Lapcharoen P, Sumroiphon S, Iwanaga S, Ushijima H, Endoh D, Miyata T, Sakata A, Kashige N, Miake F, Fukushi S, Saijo M, Kurane I, Morikawa S, Mizutani T (2007) Rapid determination of viral RNA sequences in mosquitoes collected in the field. J Virol Methods 146(1-2):372-374

20. Fernandes LN, Coletti TM, Monteiro FJC, Rego M, Ribeiro ESD, Ribeiro GO, Marinho R, Komninakis SV, Witkin SS, Deng X, Delwart E, Sabino EC, Leal E, Costa ACD (2018) A novel highly divergent strain of cell fusing agent virus (CFAV) in mosquitoes from the Brazilian Amazon region. Viruses 10(12):666

21. Zakrzewski M, Rašić G, Darbro J, Krause L, Poo YS, Filipović I, Parry R, Asgari S, Devine G, Suhrbier A (2018) Mapping the virome in wild-caught Aedes aegypti from Cairns and Bangkok. Sci Rep 8(1):4690

22. Iwashita H, Higa Y, Futami K, Lutiali PA, Njenga SM, Nabeshima T, Minakawa N (2018) Mosquito arbovirus survey in selected areas of Kenya: detection of insect-specific virus. Trop Med Health 46:19
23. Sang RC, Gichogo A, Gachoya J, Dunster MD, Ofula V, Hunt AR, Crabtree MB, Miller BR, Dunster LM (2003) Isolation of a new flavivirus related to cell fusing agent virus (CFAV) from fieldcollected flood-water Aedes mosquitoes sampled from a dambo in central Kenya. Arch Virol 148(6):1085-1093

24. Martin E, Borucki MK, Thissen J, Garcia-Luna S, Hwang M, Wise de Valdez M, Jaing CJ, Hamer GL, Frank M (2019) Mosquitoborne viruses and insect-specific viruses revealed in field-collected mosquitoes by a monitoring tool adapted from a microbial detection array. Appl Environ Microbiol 85(19):e01202-19

25. Bolling BG, Vasilakis N, Guzman H, Widen SG, Wood TG, Popov VL, Thangamani S, Tesh RB (2015) Insect-specific viruses detected in laboratory mosquito colonies and their potential implications for experiments evaluating arbovirus vector competence. Am J Trop Med Hyg 92(2):422-428

26. Crockett RK, Burkhalter K, Mead D, Kelly R, Brown J, Varnado W, Roy A, Horiuchi K, Biggerstaff BJ, Miller B, Nasci R (2012) Culex flavivirus and West Nile virus in Culex quinquefasciatus populations in the southeastern United States. J Med Entomol 49(1): 165-174

27. Kim DY, Guzman H, Bueno R Jr, Dennett JA, Auguste AJ, Carrington CV, Popov VL, Weaver SC, Beasley DW, Tesh RB (2009) Characterization of Culex flavivirus (Flaviviridae) strains isolated from mosquitoes in the United States and Trinidad. Virology 386(1):154-159

28. Blitvich BJ, Lin M, Dorman KS, Soto V, Hovav E, Tucker BJ, Staley M, Platt KB, Bartholomay LC (2009) Genomic sequence and phylogenetic analysis of Culex flavivirus, an insect-specific flavivirus, isolated from Culex pipiens (Diptera: Culicidae) in Iowa. J Med Entomol 46(4):934-941

29. Roiz D, Vazquez A, Rosso F, Arnoldi D, Girardi M, Cuevas L, Perez-Pastrana E, Sanchez-Seco MP, Tenorio A, Rizzoli A (2012) Detection of a new insect flavivirus and isolation of Aedes flavivirus in Northern Italy. Parasit Vectors 5:223

30. Krockel U, Rose A, Eiras AE, Geier M (2006) New tools for surveillance of adult yellow fever mosquitoes: comparison of trap catches with human landing rates in an urban environment. J Am Mosq Control Assoc 22(2):229-238

31. Maciel-de-Freitas R, Eiras AE, Lourenco-de-Oliveira R (2006) Field evaluation of effectiveness of the BG-Sentinel, a new trap for capturing adult Aedes aegypti (Diptera: Culicidae). Mem Inst Oswaldo Cruz 101(3):321-325

32. Mackay AJ, Amador M, Barrera R (2013) An improved autocidal gravid ovitrap for the control and surveillance of Aedes aegypti. Parasit Vectors 6(1):225

33. Barrera R, Amador M, Acevedo V, Caban B, Felix G, Mackay AJ (2014) Use of the CDC autocidal gravid ovitrap to control and prevent outbreaks of Aedes aegypti (Diptera: Culicidae). J Med Entomol 51(1):145-154

34. Barrera R, Amador M, Acevedo V, Hemme RR, Felix G (2014) Sustained, area-wide control of Aedes aegypti using CDC autocidal gravid ovitraps. Am J Trop Med Hyg 91(6):1269-1276

35. Nasci RS, Mitchell CJ (1996) Arbovirus titer variation in field-collected mosquitoes. J Am Mosq Control Assoc 12(2 Pt 1):167-171

36. Bolling BG, Olea-Popelka FJ, Eisen L, Moore CG, Blair CD (2012) Transmission dynamics of an insect-specific flavivirus in a naturally infected Culex pipiens laboratory colony and effects of co-infection on vector competence for West Nile virus. Virology 427(2):90-97

37. Moore CG, Mclean R, Mitchell CJ, Nasci RS, Tsai TF, H CC, A MA, Moore PS, Gubler DJ (1993) Guidelines for arbovirus surveillance programs in the United States

38. Williams GM, Gingrich JB (2007) Comparison of light traps, gravid traps, and resting boxes for West Nile virus surveillance. J Vector Ecol 32(2):285-291 
39. Lukacik G, Anand M, Shusas EJ, Howard JJ, Oliver J, Chen H, Backenson PB, Kauffman EB, Bernard KA, Kramer LD, White DJ (2006) West Nile virus surveillance in mosquitoes in New York State, 2000-2004. J Am Mosq Control Assoc 22(2):264-271

40. Ginsberg HS, Rochlin I, Campbell SR (2010) The use of early summer mosquito surveillance to predict late summer West Nile virus activity. J Vector Ecol 35(1):35-42

41. Oliveira JH, Goncalves RL, Lara FA, Dias FA, Gandara AC, Menna-Barreto RF, Edwards MC, Laurindo FR, Silva-Neto MA, Sorgine MH, Oliveira PL (2011) Blood meal-derived heme decreases ROS levels in the midgut of Aedes aegypti and allows proliferation of intestinal microbiota. PLoS Pathog 7(3):e1001320

42. Noriega FG, Pennington JE, Barillas-Mury C, Wang XY, Wells MA (1996) Aedes aegypti midgut early trypsin is post-transcriptionally regulated by blood feeding. Insect Mol Biol 5(1):25-29

43. Kokoza V, Ahmed A, Cho WL, Jasinskiene N, James AA, Raikhel A (2000) Engineering blood meal-activated systemic immunity in the yellow fever mosquito, Aedes aegypti. Proc Natl Acad Sci USA 97(16):9144-9149

44. Saiyasombat R, Bolling BG, Brault AC, Bartholomay LC, Blitvich BJ (2011) Evidence of efficient transovarial transmission of Culex flavivirus by Culex pipiens (Diptera: Culicidae). J Med Entomol 48(5):1031-1038

45. Bolling BG, Eisen L, Moore CG, Blair CD (2011) Insect-specific flaviviruses from Culex mosquitoes in Colorado, with evidence of vertical transmission. Am J Trop Med Hyg 85(1):169-177

46. Haddow AD, Guzman H, Popov VL, Wood TG, Widen SG, Haddow AD, Tesh RB, Weaver SC (2013) First isolation of Aedes flavivirus in the Western Hemisphere and evidence of vertical transmission in the mosquito Aedes (Stegomyia) albopictus (Diptera: Culicidae). Virology 440(2):134-139
47. Lutomiah JJ, Mwandawiro C, Magambo J, Sang RC (2007) Infection and vertical transmission of Kamiti river virus in laboratory bred Aedes aegypti mosquitoes. J Insect Sci 7:1-7

48. Kent RJ, Crabtree MB, Miller BR (2010) Transmission of West Nile virus by Culex quinquefasciatus say infected with Culex Flavivirus Izabal. PLoS Negl Trop Dis 4(5):e671

49. Kenney JL, Solberg OD, Langevin SA, Brault AC (2014) Characterization of a novel insect-specific flavivirus from Brazil: potential for inhibition of infection of arthropod cells with medically important flaviviruses. J Gen Virol 95(Pt 12):2796-2808

50. Goenaga S, Kenney JL, Duggal NK, Delorey M, Ebel GD, Zhang B, Levis SC, Enria DA, Brault AC (2015) Potential for co-infection of a mosquito-specific flavivirus, Nhumirim virus, to block West Nile virus transmission in mosquitoes. Viruses 7(11):5801-5812

51. Zhang G, Asad S, Khromykh AA, Asgari S (2017) Cell fusing agent virus and dengue virus mutually interact in Aedes aegypti cell lines. Sci Rep 7(1):6935

52. Baidaliuk A, Miot EF, Lequime S, Moltini-Conclois I, Delaigue F, Dabo S, Dickson LB, Aubry F, Merkling SH, Cao-Lormeau VM, Lambrechts L (2019) Cell-fusing agent virus reduces arbovirus dissemination in Aedes aegypti mosquitoes in vivo. J Virol 93(18):e00705-19

Publisher's Note Springer Nature remains neutral with regard to jurisdictional claims in published maps and institutional affiliations. 